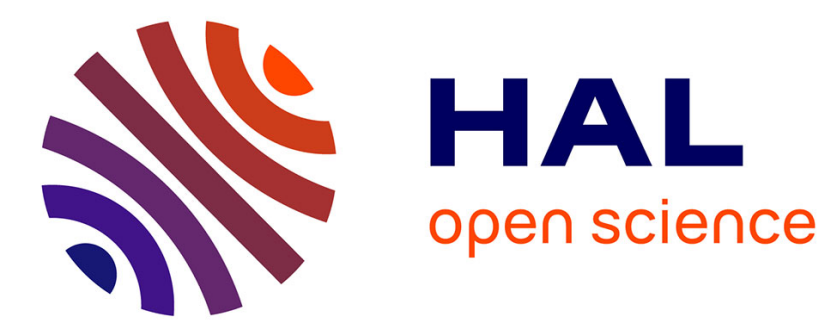

\title{
LXR antagonists induce ABCD2 expression
}

Catherine Gondcaille, Emmanuelle C. Genin, Tatiana E. Lopez, Alexandre M.M. Dias, Flore Geillon, Pierre Andreoletti, Mustapha Cherkaoui-Malki, Thomas Nury, Gérard Lizard, Isabelle Weinhofer, et al.

\section{- To cite this version:}

Catherine Gondcaille, Emmanuelle C. Genin, Tatiana E. Lopez, Alexandre M.M. Dias, Flore Geillon, et al.. LXR antagonists induce ABCD2 expression. Biochimica et Biophysica Acta Molecular and Cell Biology of Lipids, 2014, 1841 (2), pp.259-266. 10.1016/j.bbalip.2013.11.003 . hal-01185659

\section{HAL Id: hal-01185659 \\ https://hal.science/hal-01185659}

Submitted on 20 Aug 2015

HAL is a multi-disciplinary open access archive for the deposit and dissemination of scientific research documents, whether they are published or not. The documents may come from teaching and research institutions in France or abroad, or from public or private research centers.
L'archive ouverte pluridisciplinaire HAL, est destinée au dépôt et à la diffusion de documents scientifiques de niveau recherche, publiés ou non, émanant des établissements d'enseignement et de recherche français ou étrangers, des laboratoires publics ou privés. 


\title{
LXR antagonists induce $A B C D 2$ expression
}

\author{
Catherine Gondcaille ${ }^{\mathrm{a}, 1}$, Emmanuelle C. Genin ${ }^{\mathrm{a}, 1}$, Tatiana E. Lopez ${ }^{\mathrm{a}}$, Alexandre M.M. Dias a \\ Flore Geillon ${ }^{a}$, Pierre Andreoletti ${ }^{a}$, Mustapha Cherkaoui-Malki ${ }^{a}$, Thomas Nury ${ }^{a}$, Gérard Lizard ${ }^{a}$, \\ Isabelle Weinhofer ${ }^{\mathrm{b}}$, Johannes Berger ${ }^{\mathrm{b}}$, Eili T. Kase ${ }^{\mathrm{c}}$, Doriane Trompier ${ }^{\mathrm{a}}$, Stéphane Savary ${ }^{\mathrm{a}, *}$ \\ a Laboratoire Bio-PeroxIL, EA7270 University of Burgundy, 6 Bd Gabriel, Dijon F-21000, France \\ b Center for Brain Research, Medical University of Vienna, Spitalgasse 4, A-1090 Vienna, Austria \\ c Department of Pharmaceutical Biosciences, School of Pharmacy, University of Oslo, Norway
}

\section{A R T I C L E I N F O}

\section{Article history:}

Received 10 July 2013

Received in revised form 25 October 2013

Accepted 6 November 2013

Available online 13 November 2013

\section{Keywords:}

$\mathrm{X}-\mathrm{ALD}$

Very-long-chain fatty acid

LXR

Hydroxycholesterol

$\mathrm{ABCD} 2$

\begin{abstract}
A B S T R A C T
$\mathrm{X}$-linked adrenoleukodystrophy (X-ALD) is a rare neurodegenerative disorder characterized by the accumulation of very-long-chain fatty acids resulting from a $\beta$-oxidation defect. Oxidative stress and inflammation are also key components of the pathogenesis. X-ALD is caused by mutations in the $A B C D 1$ gene, which encodes for a peroxisomal half $A B C$ transporter predicted to participate in the entry of VLCFA-COA into the peroxisome, the unique site of their $\beta$-oxidation. Two homologous peroxisomal $A B C$ transporters, $A B C D 2$ and $A B C D 3$ have been proven to compensate for ABCD1 deficiency when overexpressed. Pharmacological induction of these target genes could therefore represent an alternative therapy for X-ALD patients. Since LXR activation was shown to repress $A B C D 2$ expression, we investigated the effects of LXR antagonists in different cell lines. Cells were treated with GSK(17) (a LXR antagonist recently discovered from the GlaxoSmithKline compound collection), 22(S)hydroxycholesterol (22S-HC, another LXR antagonist) and 22R-HC (an endogenous LXR agonist). We observed up-regulation of $A B C D 2, A B C D 3$ and $C T N N B 1$ (the gene encoding for $\beta$-catenin, which was recently demonstrated to induce $A B C D 2$ expression ) in human HepG2 hepatoma cells and in X-ALD skin fibroblasts treated with LXR antagonists. Interestingly, induction in X-ALD fibroblasts was concomitant with a decrease in oxidative stress. Rats treated with 22S-HC showed hepatic induction of the 3 genes of interest. In human, we show by multiple tissue expression array that expression of $A B C D 2$ appears to be inversely correlated with NR1H3 (LXR $\alpha)$ expression. Altogether, antagonists of LXR that are currently developed in the context of dyslipidemia may find another indication with X-ALD.
\end{abstract}

(c) 2013 Elsevier B.V. All rights reserved.

\section{Introduction}

X-linked adrenoleukodystrophy (X-ALD, OMIM 300100) is the most frequent peroxisomal disorder with an incidence of $1 / 17,000$ births $[1,2]$. The biochemical hallmark of this neurodegenerative disease is the accumulation of very-long-chain fatty acids (VLCFA, fatty acids with a carbon chain longer than 22 carbons) in plasma and tissues resulting from a $\beta$-oxidation defect. Oxidative stress and inflammation are also key components of the pathogenesis of X-ALD. However, the exact link

Abbreviations: ACOX, Acyl-CoA oxidase; ABC, ATP binding cassette; DHA docosahexaenoic acid (C22:6 n-3); H2DCFDA, 2',7'-dichlorodihydrofluorescein diacetate; HC, hydroxycholesterol; HFD, high fat diet; LXR, Liver X receptor; LXRE, LXR response element; MTE, multiple tissue expression; MUFA, monounsaturated fatty acids; PPAR, peroxisome proliferator activated receptor; PUFA, Polyunsaturated Fatty acids; ROS, reactive oxygen species; SREBP, sterol regulatory element binding protein; TcF, T cell factor; T3, triiodothyronine; T4, thyroxine; TR, thyroid hormone receptor; TRE, thyroid hormone response element; VLCFA, very-long-chain fatty acids; X-ALD, X-linked adrenoleukodystrophy

* Corresponding author at: Laboratoire Bio-PeroxIL, EA7270 University of Burgundy, 6 Bd Gabriel, Dijon, F-21000, France. Tel.: + 33 380396273; fax: + 33380396250

E-mail address: stsavary@u-bourgogne.fr (S. Savary).

1 Co 1 st author. between VLCFA accumulation, demyelination, oxidative stress and inflammation as well as the sequence of events leading to the disease are still unclear. X-ALD is caused by mutations in $A B C D 1$ gene located in $\mathrm{Xq} 28$ [3]. $A B C D 1$ encodes for a peroxisomal half $A B C$ transporter, which is responsible for the entry of very-long-chain fatty acyl-CoA into the peroxisome, the unique site of their $\beta$-oxidation [4]. Two homologous peroxisomal $A B C$ transporters, $A B C D 2[5,6]$ and $A B C D 3$ [7], have been proven to compensate for $\mathrm{ABCD} 1$ deficiency when overexpressed in $\mathrm{X}$ ALD fibroblasts [8-11]. Functional redundancy is also recognized in vivo since reversion of the adrenomyeloneuropathy-like phenotype has been observed in Abcd1 null mice overexpressing $A b c d 2$ in a ubiquitous manner [12]. Several studies have suggested that $A B C D 2$ plays a role not only in the transport of long and very-long-chain saturated fatty acids, but also in the transport of monounsaturated and polyunsaturated fatty acids (PUFA) [13-16]. Actually, the function of ABCD2 appears to be central for lipid homeostasis as suggested by the fact that the $A B C D 2$ gene is a target of numerous regulation pathways in relation with lipid metabolism. The $A B C D 2$ gene is up-regulated by cholesterol depletion via SREBP [17], by PPAR $\alpha$ activators such as fibrates [18], by thyroid hormone and thyromimetics [19-21], by dehydroepiandrosterone [22], by PUFA diets [23], and by inhibitors of histone deacetylases such as 4- 
phenylbutyrate [24,25] or valproic acid [26]. The promoter analysis of the $A B C D 2$ gene led us to identify a direct repeat motif with a 4 bp spacer as a functional thyroid hormone response element (TRE) [19]. This motif is also known as a response element for the Liver X receptor (LXR), a nuclear receptor for oxysterols [27]. We therefore investigated whether the $A B C D 2$ promoter could be responsive to LXR ligands and identified LXR $\alpha$ as a negative modulator of $A B C D 2$ expression [28]. Moreover, this study revealed a complex cross-talk involving key actors of the lipid metabolism (TRs, LXRs and SREBPs) since the TRE/LXRE motif of the ABCD2 promoter overlaps a SRE motif. $L X R \alpha$, upon ligand binding, was shown to interfere with SREBP1c-mediated activation of the $A b c d 2$ promoter. Very recently, $\beta$-catenin and TCF- 4 , which are important components of the Wnt signaling pathway, were described as inducers of the $A B C D 2$ expression [29]. Interestingly, the Wnt components are known to be repressed by oxysterols $[30,31]$.

Numerous studies have been conducted to identify LXR ligands that could be used to treat dyslipidemia. Screening of the GlaxoSmithKline compound collection resulted in the discovery of an LXR antagonist (GSK1440233A, compound 17) [32]. This synthetic molecule antagonized the expression of LXR target genes in HepG2 and THP1 cells with apparent IC50 values less than $100 \mathrm{nM}$. GSK(17), as well as 22Shydroxycholesterol (22S-HC), another antagonist of LXR described to reduce lipogenesis and formation of complex lipids and free cholesterol [33], could therefore be considered in the context of X-ALD.

In this study, we explored the effects of LXR antagonists (GSK(17) or 22S-HC) in human hepatoma cells and human skin fibroblasts from $\mathrm{X}$-ALD patients to see whether these LXR antagonists can induce $A B C D 2$ expression or other target genes $(A B C D 3, A C O X 1$, which encodes for the key enzyme of the peroxisomal $\beta$-oxidation, and CTNNB1 which encodes for $\beta$-catenin). In X-ALD fibroblasts, we also investigated whether the treatments modulate oxidative status and fatty acid content. The results were compared with those obtained from a treatment with 22R-HC, an endogenous LXR agonist. Expression of $A b c d 2, A b c d 3$ and Ctnnb1 genes and other LXR target genes (Abca1 and Srebp1) in liver from control rats or rats treated with 22S-HC was also analyzed. Finally, we investigated and compared the expression level of $A B C D 2$ and NR1H3 (encoding for LXR $\alpha$ ) genes in human tissues.

\section{Materials and methods}

\subsection{Cell culture and treatments}

Human HepG2 (Human hepatoma cell line, ATCC HB-8065), human skin X-ALD fibroblasts (ALD-3 cell line or Coriell Institute GM17819) and WT human skin fibroblasts (Coriell Institute GM03348) were grown in Dulbecco's modified Eagle's medium supplemented with $10 \%$ fetal bovine serum at $37{ }^{\circ} \mathrm{C}$ under $5 \% \mathrm{CO}_{2}$ in the absence of antibiotics. The ALD-3 cell line [9], which is a non-transformed cell line with a large deletion in the $A B C D 1$ gene was kindly provided by Dr. A. Pujol, Barcelona, (Spain). Cells at $80 \%$ confluence were treated during 3 days with LXR ligands and the medium was changed daily. 22R-HC and 22S-HC (Sigma) were used at $10 \mu \mathrm{M}$ in ethanol from a stock solution prepared at $10 \mathrm{mM}$ in ethanol. GSK(17) (GSK1440233A) kindly provided by Dr. William J. Zuercher (GlaxoSmithKline), was used at $100 \mathrm{nM}$ in DMSO from a stock solution at $100 \mu \mathrm{M}$ in DMSO.

\subsection{The 22-S-hydroxycholesterol-effect study in Wistar rats}

The details of this animal study have been previously published [34]. In summary, male Wistar rats were fed ad libitum a regular maintenance diet (Special Diets Services, Witham, Essex, UK) for 5 days after arrival to our animal facilities. Then a feeding regimen was adopted using high-fat diet (HFD) for 21 days. The rats were about 9 weeks old at the start of the experimental feeding. Wistar rats were randomly divided into two groups with 6 animals each, receiving HFD $\pm 22 \mathrm{~S}-\mathrm{HC}$ ( $30 \mathrm{mg} / \mathrm{kg} / \mathrm{day}$ ) for 21 days. There were 3 animals in each cage and they had free access to tap water. The experimental protocol (Id: 823) was approved by the National Animal Research Authority. Immediately after termination of the animals, tissues were collected.

\subsection{RT-qPCR analysis from treated cells}

Cells were harvested with $0.25 \%$ trypsin/EDTA (Sigma) and washed twice with PBS. Total RNA was isolated and treated with DNase to discard genomic DNA using the RNeasy Mini kit (Qiagen) following manufacturer's instruction. After quantification and verification of their quality by gel electrophoresis, $1 \mu \mathrm{g}$ of RNA was reverse transcribed to generate cDNA using the "iScript cDNA synthesis kit" (Bio-Rad). These cDNA were further analyzed by quantitative PCR using the SYBR Green real-time PCR technology and a StepOne Plus system (Applied Biosystems). PCR reactions were carried out in duplicate in a final volume of $25 \mu$ containing $12.5 \mu \mathrm{l}$ of GoTaq qPCR Mastermix (Promega), $300 \mathrm{nM}$ of forward and reverse primers and $5 \mu \mathrm{l}$ of diluted cDNA (dilution 1/20 for $A b c d 2$ gene or dilution 1/40 for the other genes). The PCR enzyme ( Taq DNA polymerase) was heat-activated at $95^{\circ} \mathrm{C}$ for $2 \mathrm{~min}$, and the DNA was amplified for 40 cycles at $95^{\circ} \mathrm{C}$ for $15 \mathrm{~s}$ and $60{ }^{\circ} \mathrm{C}$ for $1 \mathrm{~min}$, followed by a melting curve analysis to control the absence of non-specific products. For each transcript, the amplification efficiency was determined by the slope of the standard curve generated from 2fold serial dilutions of cDNA. Quantification of gene expression was performed using Cycle to threshold $(\mathrm{Ct})$ values and normalized by the $36 \mathrm{~B} 4$ gene. Primers for human $(\mathrm{h})$ genes were chosen using the Primer Express software program (Applied Biosystems) and purchased from Eurogentec: hABCD2: F, 5'-GAACTGCTGTCATTCAAGAATCTG-3', R, 5'TGCCAATGTGTCACTGAGAGG-3'; hABCD3: F, 5'-GTGGTATCATTGGTCG TAGCAG-3', R, 5'-AGCCTTACTCGGAAGCACAG-3'; hACOX1: F, 5'-CCTG AGCCTCTGGATCTTCAC-3', R, 5'-GGTGAGTTCCATGACCCATCTCTG-3'; hCTNNB1: F, 5'-ATGTCGAGCGTTTGGCTGAA-3', R, 5'-TGGTCCTCGTCA TTTAGCAGTT-3'; h36B4: F, 5'-CTCCTTTGGGCTGGTCATCC-3', R, 5'CAGACAGACACTGGCAACATTG-3'.

\section{4. $R T-q P C R$ analysis from treated rats}

Liver was collected from each rat and stored at $-70^{\circ} \mathrm{C}$. The tissues were homogenized and total RNA were isolated and reversely transcribed as previously described [34]. Real time qPCR was performed using an ABI PRISM ${ }^{\circledR} 7000$ Detection System. DNA expression was determined using the SYBR Green real-time PCR technology. Primers (rAbcd2: F, 5'-CAGCGTCCACCTCTACCACATAG-3', R, 5'-CGTCCAGCAA TGCGTACTTCG-3'; rAbcd3: F, 5'-GGCTGGGCGTGAAATGACTA-3', R, 5' GCCATTTGGACCACAAATGA-3'; r36B4: F, 5'-CACCTTCCCACTGGCTGA AA-3', R, 5'-CGCAGCCGCAAATGC-3'; rCtnnb1: F, 5'-CTGATAAAGGCAAC TGTTGGA-3', R, 5'-CCCTGTTCCCGCAAAGG-3'; rAbcA1: F, 5'-GTGTTTCT CAGAGCAGTTCTGA-3', R, 5'-CGTGCCCAATGTCCTCCA-3'; rSrebp1: F, 5' GGAGCCATGGATTGCACATT-3', R, 5'-CCTGTCTCACCCCCAGCATA-3') were designed using Primer Express ${ }^{\circledR}$ (Applied Biosystems) and purchased from Invitrogen. Each target gene was quantified in duplicates and carried out in a $25 \mu \mathrm{l}$ reaction volume according to the supplier's protocol. All assays were run for 40 cycles $\left(95^{\circ} \mathrm{C}\right.$ for $12 \mathrm{~s}$ followed by $60{ }^{\circ} \mathrm{C}$ for $60 \mathrm{~s}$ ). The transcription levels were normalized to the housekeeping control gene $36 \mathrm{~B} 4$.

\subsection{Oxidative stress assessed by flow cytometry}

The whole intracellular ROS production was analyzed using the $2^{\prime}, 7^{\prime}$-dichlorodihydrofluorescein diacetate probe $\left(\mathrm{H}_{2} \mathrm{DCFDA}\right)$. This non-fluorescent compound passively diffuses into cells where its acetate groups are cleaved by intracellular esterases and its thiol-reactive chloromethyl group reacts with intracellular glutathione and other thiols. Subsequent oxidation yields a fluorescent adduct that is trapped inside the cell and can be monitored by flow cytometry. Treated X-ALD fibroblasts or WT fibroblasts as reference (confluence 60\% in 6-well 
plate) were incubated for $30 \mathrm{~min}$ at $37{ }^{\circ} \mathrm{C}$ with $10 \mu \mathrm{M} \mathrm{H}_{2} \mathrm{DCFDA}$, trypsinized with $0.25 \%$ trypsin/EDTA (Sigma), harvested in $1 \mathrm{~mL}$ PBS before flow cytometric analysis. A ROS production positive control was performed by a pre-incubation for $1 \mathrm{~h}$ at $37^{\circ} \mathrm{C}$ with $50 \mu \mathrm{M}$ antimycin A. For each sample, 10,000 cells were acquired, and the data were analyzed with FlowJo (Tree Star Inc.) software.

\subsection{Fatty acid analyses}

Fatty acid contents of X-ALD fibroblasts (ALD-3 or Coriell Institute GM17819 cell lines) under LXR-antagonists treatments were analyzed as pentafluorobenzyl esters by gas chromatography/mass spectrometry in negative chemical ionization mode as previously described [35].

\subsection{Human multiple tissue array analyses}

A multiple tissue expression (MTE) array containing poly(A)-selected RNA from 61 different adult human tissues was obtained from Clontech. For detection of human $A B C D 2$ mRNA, a cDNA fragment corresponding to bp 172-1124 of the human $A B C D 2$ cDNA sequence (accession no. AJ000327) was amplified by PCR reaction from plasmid p115 containing the full-length human $A B C D 2$ using the following primers: F, 5'-AAATGG ACCAGATCGAGTGCTGC-3' and R, 5'-CAAAGCTTTAGCAGATCAGAT-3'. For detection of human NR1H3 (LXR $\alpha)$ mRNA, an $1.4 \mathrm{~kb}$ cDNA probe was prepared by digesting plasmid p301 containing the full-length human NR1H3 CDNA, which was kindly provided by Dr. David Mangelsdorf (UT Southwestern, Texas). For control, a 528-bp glyceraldehyde-3phosphatedehydrogenase $(G A P D H)$ probe was prepared by PCR using 5'-ACCACCATGGAGAAGGCTGG-3' and 5'-CTCAGTGTAGCCCAGG ATGC-3' as forward and reverse primers, respectively. The probes were radioactively labeled by random priming using $\left[\alpha{ }^{32} \mathrm{P}\right] \mathrm{dCTP}$ and hybridized using ExpressHyb solution (BD Bioscience) before autoradiographic exposure to a phosphoimager system (Bio-Rad). Signal intensity of individual dots was quantified using ImageJ software (available from: http:// rsbweb.nih.gov/ij/download.html), and the $A B C D 2$ or NR1H3 expression relative to that of $G A P D H$ was calculated.

\subsection{Statistical analysis}

Student's $t$-test was used for statistical analysis. $\mathrm{p}<0.05$ was considered statistically significant.

\section{Results}

\subsection{Effects of LXR antagonists on gene expression in HepG2 cells}

Since HepG2 hepatoma cells have been used in numerous studies to investigate the effects of LXR activation, this prompted us to analyze the effects of LXR antagonists on gene expression by RT-qPCR in this human cell line. No sign of toxicity was observed at $10 \mu \mathrm{M}$ for $22 \mathrm{~S}-\mathrm{HC}$ and $22 \mathrm{R}-$ $\mathrm{HC}$ and at $100 \mathrm{nM}$ for GSK(17) (data not shown). Quantitative real time PCR analysis was performed after 3 days of treatment. Both GSK(17) and $22 \mathrm{~S}-\mathrm{HC}$ treatments significantly up-regulated the $A B C D 2$ expression level by 1.47 - and 1.97 -fold, respectively (Fig. 1). As expected, $A B C D 2$ expression was down-regulated by $22 \mathrm{R}-\mathrm{HC}$ ( 0.57 -fold). $A B C D 3$ expression was found significantly increased by $22 \mathrm{~S}-\mathrm{HC}$ treatment but not significantly modified by GSK(17) and 22R-HC (Fig. 1). While ACOX1 expression was not significantly affected by the treatments, CTNNB1 ( $\beta$-catenin) expression followed the same pattern than $A B C D 2$ (Fig. 1).

\subsection{Effects of LXR antagonists on gene expression in $X-A L D$ fibroblasts}

In order to evaluate the effects of LXR ligands in the context of $X-A L D$, the same experiments were carried out in human skin fibroblasts derived from an X-ALD patient (ALD-3 cell line [9]). As shown
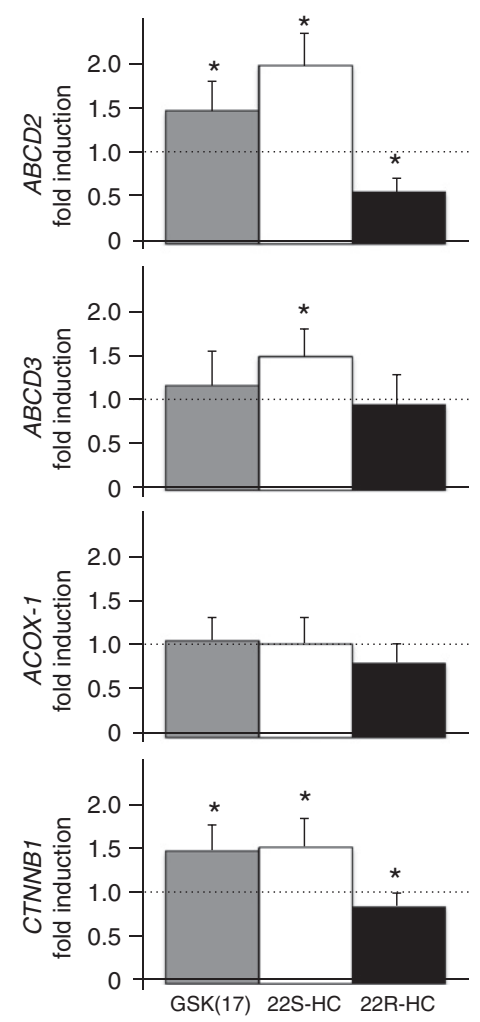

Fig. 1. LXR antagonists (GSK(17) or 22S-HC) induce $A B C D 2, A B C D 3$ and $C T N N B 1$ ( $\beta$-catenin) gene expression in human HepG2 hepatoma cells treated during 3 days. The mRNA levels of $A B C D 2, A B C D 3, A C O X 1$ and $C T N N B 1$ were measured using real time RT-qPCR and normalized to 36B4. Data represent the mean \pm SD of 4 to 6 experiments and are expressed as fold induction in comparison with the gene expression level in untreated cells taken arbitrary equal to 1 . Statistically significant differences from control by student $t$ test are indicated by asterisks $\left({ }^{*} \mathrm{p}<0.01\right)$.

in Fig. 2, similar results to those obtained in HepG2 cells were observed. $A B C D 2$ expression was significantly increased by 1.57 -fold with GSK(17) and by 1.68 -fold with $22 \mathrm{~S}$-HC while it was reduced by $0.60-$ fold with $22 \mathrm{R}-\mathrm{HC}$. $A B C D 3$ expression was only moderately induced by 22S-HC treatment while ACOX1 expression was not modified (Fig. 2). The expression level of CTNNB1 was found weakly induced upon 22S$\mathrm{HC}$ and GSK(17) treatment and remained unchanged with 22R-HC (Fig. 2). These results are in accordance with those obtained with HepG2 cells revealing the specific activation (derepression) of $A B C D 2$ and $A B C D 3$ gene expression by LXR antagonists.

\subsection{Effects of LXR antagonists on oxidative stress and VLCFA content in $X-A L D$ fibroblasts}

Oxidative stress has been found to be increased in X-ALD fibroblasts as compared with control fibroblasts [36]. This increase associated with $A B C D 1$ deficiency is predicted to be caused and amplified by VLCFA accumulation [37]. The observed induction of $A B C D 2$ and, to a lesser extent, of $A B C D 3$, upon treatment with LXR antagonists may therefore compensate for $\mathrm{ABCD} 1$ deficiency and improve both the oxidative status and the VLCFA levels. On the contrary, the 22R-HC treatment may amplify oxidative stress and VLCFA accumulation. To test these hypotheses, we treated the ALD-3 and the Coriell X-ALD human skin fibroblasts during $72 \mathrm{~h}$ with $10 \mu \mathrm{M}$ of $22 \mathrm{R}-\mathrm{HC}$ or $22 \mathrm{~S}-\mathrm{HC}$ or with $100 \mathrm{nM}$ of GSK(17). The fatty acid content was quantified by GC/MS in treated cells and reported to the fatty acid content observed in untreated cells. As shown in Table 1, we did not notice significant effects for the saturated VLCFA. Although results did not reach statistical significance threshold, it is noteworthy that monounsaturated fatty acids (MUFA, C20:1, C22:1 and C24:1) tended to decrease under treatment with 


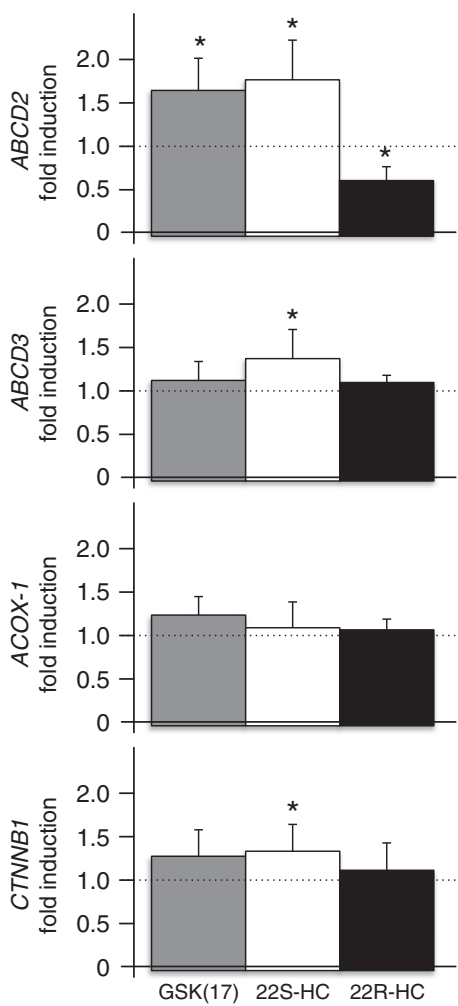

Fig. 2. LXR antagonists (GSK(17) or 22S-HC) induce $A B C D 2, A B C D 3$ and $C T N N B 1$ ( $\beta$-catenin) gene expression in human X-ALD fibroblasts treated during 3 days. The mRNA levels of $A B C D 2, A B C D 3, A C O X 1$ and $C T N B B 1$ were measured using real time RT-qPCR and normalized to 36B4. Data represent the mean \pm SD of 4 to 6 experiments and are expressed as fold induction in comparison with the gene expression level in untreated cells taken arbitrary equal to 1 . Statistically significant differences from control by student $t$ test are indicated by asterisks $\left({ }^{*} \mathrm{p}<0.01\right)$.

LXR antagonists while their levels increased under treatment with 22RHC (Table 1). The level of C24:6n-3, the immediate precursor of DHA (C22:6n-3), was shown to be reduced in cells treated by LXR antagonists (the decrease was only significant in Coriell cells treated with 22S$\mathrm{HC}$ ). The oxidative status analyzed by flow cytometry assay using the $\mathrm{H}_{2}$ DCFDA probe displayed significant modifications. In ALD-3 cells, both LXR antagonists triggered a significant decrease of ROS as compared with control cells, while $22 \mathrm{R}-\mathrm{HC}$ treatment yield a 1.68 -fold increase (Fig. 3). Similar results were obtained with the Coriell X-ALD cell line even if significant results were observed only for the 22S-HC

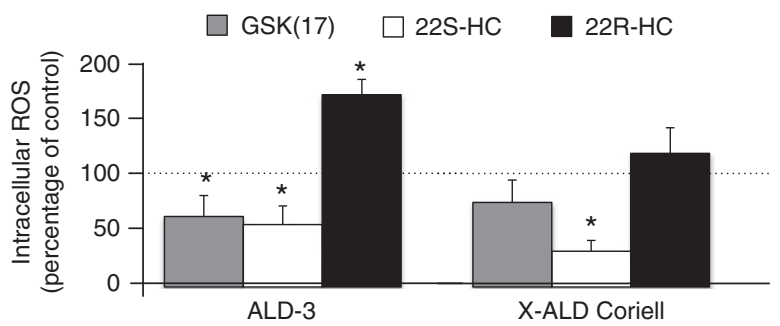

Fig. 3. LXR antagonists (GSK(17) or 22S-HC) decrease oxidative stress in human X-ALD fibroblasts treated during 3 days. The intracellular ROS production was analyzed using the $\mathrm{H}_{2}$ DCFDA probe as described in Materials and methods. Data represent the mean \pm SD of 3-5 experiments and are expressed as percentage of control in comparison with the ROS production level in untreated cells taken arbitrary equal to 100 . Statistically significant differences from control by student $t$ test are indicated by asterisks ( ${ }^{*} \mathrm{p}<0.01$ ).

treatment (Fig. 3). Thus, the use of LXR antagonists may participate to lower ROS production and oxidative stress.

\subsection{Effects of dietary 22S-HC on hepatic expression}

The expression levels of carnitine palmitoyl transferase 2 and uncoupling protein 3 have been shown to be induced in liver of rats fed a normal or high fat diet enriched in $22 \mathrm{~S}-\mathrm{HC}(30 \mathrm{mg} / \mathrm{kg} / \mathrm{day}$ for 3 weeks) [34]. In order to study whether 22S-HC could induce hepatic expression of $A b c d 2, A b c d 3$ or Ctnnb1 in vivo, cDNA samples from these rats were analyzed by RT-qPCR. In concordance with the results from the in vitro cell assays (in X-ALD fibroblasts and HepG2 cells), we observed a moderate but significant increase in expression of $\mathrm{Abcd} 3$ (1.51-fold) and Ctnnb1 (1.39-fold) after exposure to 22S-HC (Fig. 4). Although at the limit of significance $(\mathrm{p}=0.07), A b c d 2$ hepatic expression was found considerably increased (9.66-fold). The expression levels of Abca1 and Srebp1, two known LXR target genes, were also analyzed and found unchanged by the treatment (data not shown).

\subsection{Compared tissue expression of NR1H3 ( $L X R \alpha)$ and $A B C D 2$ in human}

We have shown that treatments with LXR antagonists trigger induction of $A b c d 2$ and $A b c d 3$ genes in vitro in human cells and in vivo in rat liver. Based on these findings, we investigated and compared the expression level of $A B C D 2$ and $N R 1 H 3(L X R \alpha)$ genes in a large variety of human tissues using the multiple tissue expression (MTE) array containing poly(A)-selected RNA from 61 different tissues of human origin (Clontech). Dot blot quantification in tissues with the NR1H3 highest

Table 1

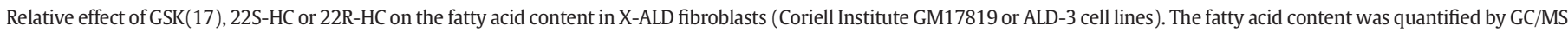

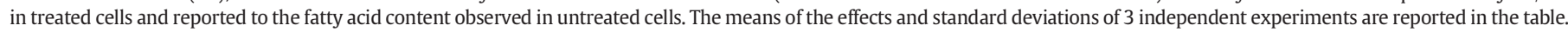
Statistically significant differences from control by student $t$ test are indicated by asterisks $\left({ }^{*} \mathrm{p}<0.05\right)$.

\begin{tabular}{|c|c|c|c|c|c|c|c|c|c|c|c|c|}
\hline \multicolumn{7}{|c|}{ ALD Coriell (GM17819) } & \multicolumn{6}{|l|}{ ALD-3 } \\
\hline & \multicolumn{2}{|c|}{ GSK(17) } & \multicolumn{2}{|c|}{$22 \mathrm{~S}-\mathrm{HC}$} & \multicolumn{2}{|c|}{ 22R-HC } & \multicolumn{2}{|c|}{ GSK(17) } & \multicolumn{2}{|c|}{$22 \mathrm{~S}-\mathrm{HC}$} & \multicolumn{2}{|c|}{ 22R-HC } \\
\hline & Mean & SD & Mean & SD & Mean & SD & Mean & SD & Mean & SD & Mean & SD \\
\hline C20:0 & 1.10 & 0.25 & 1.02 & 0.37 & 1.08 & 0.32 & 1.07 & 0.14 & 1.09 & 0.15 & 1.27 & 0.25 \\
\hline $\mathrm{C} 22: 0$ & 0.79 & 0.23 & 0.87 & 0.34 & 1.26 & 0.32 & 1.08 & 0.18 & 1.10 & 0.51 & 0.86 & 0.21 \\
\hline $\mathrm{C} 24: 0$ & 0.94 & 0.26 & 1.09 & 0.39 & 1.10 & 0.22 & 1.04 & 0.19 & 0.97 & 0.19 & 0.75 & 0.20 \\
\hline C26:0 & 1.19 & 0.40 & 1.04 & 0.08 & 0.98 & 0.15 & 1.13 & 0.19 & 1.36 & 0.17 & 1.05 & 0.30 \\
\hline$C 20: 1 n-9$ & 1.04 & 0.02 & 0.63 & 0.09 & 1.58 & 0.44 & 0.87 & 0.10 & 0.81 & 0.23 & 1.30 & 0.23 \\
\hline $\mathrm{C} 22: 1 \mathrm{n}-9$ & 1.12 & 0.49 & 0.46 & 0.001 & 1.72 & 0.96 & 0.79 & 0.12 & 0.60 & 0.21 & 1.32 & 0.23 \\
\hline$C 24: 1 n-9$ & 0.92 & 0.07 & 0.63 & 0.16 & 1.38 & 0.15 & 0.85 & 0.11 & 0.76 & 0.26 & 1.06 & 0.20 \\
\hline$C 26: 1 n-9$ & 1.15 & 0.35 & 1.11 & 0.12 & 1.56 & 0.64 & 0.92 & 0.09 & 1.03 & 0.31 & 1.36 & 0.30 \\
\hline$C 20: 5 n-3$ & 1.04 & 0.11 & 0.93 & 0.10 & 1.66 & 0.34 & 0.93 & 0.10 & 1.41 & 0.42 & 1.74 & 0.43 \\
\hline$C 22: 6 n-3$ & 1.16 & 0.26 & 0.78 & 0.05 & 1.38 & 0.41 & 1.00 & 0.12 & 0.95 & 0.14 & 1.18 & 0.19 \\
\hline$C 24: 6 n-3$ & 0.76 & 0.43 & $0.53^{*}$ & 0.10 & 1.21 & 0.39 & 0.93 & 0.10 & 0.54 & 0.09 & 0.90 & 0.17 \\
\hline$C 20: 4 n-6$ & 1.05 & 0.27 & 0.89 & 0.03 & 1.44 & 0.70 & 0.91 & 0.14 & 1.21 & 0.44 & 1.23 & 0.26 \\
\hline$C 22: 5 n-6$ & 1.39 & 0.60 & 0.76 & 0.02 & 1.37 & 0.61 & 0.99 & 0.13 & 0.91 & 0.21 & 1.02 & 0.23 \\
\hline
\end{tabular}



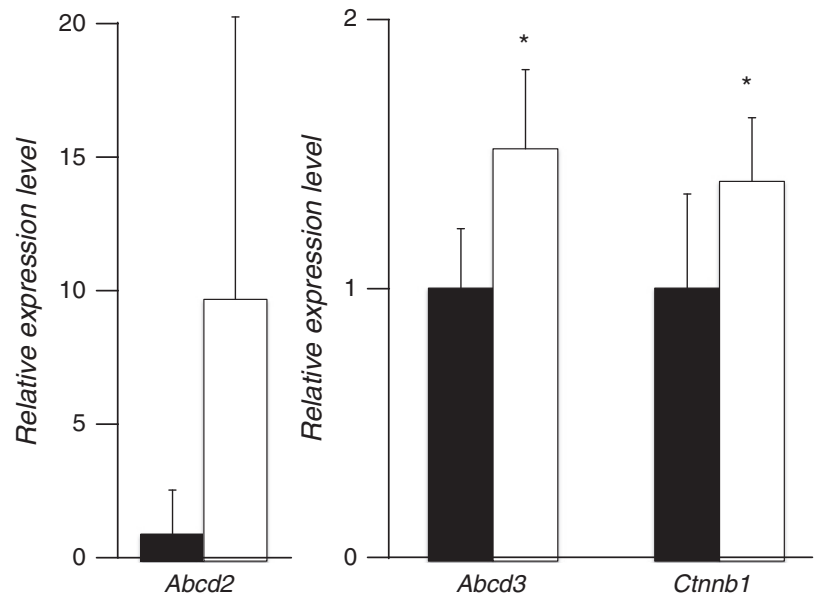

Fig. 4. 22S-HC induces $A b c d 2, A b c d 3$ and $C t n b b 1$ ( $\beta$-catenin) gene expression in rat liver Rats were randomly divided into 2 groups with 6 animals each, receiving high-fat diet (HFD) $\pm 22 \mathrm{~S}$-HC for 21 days. Tissue samples were prepared as described in Methods. Total RNA was extracted, reversely transcribed and analyzed by RT-qPCR. Results are normalized to levels of $36 B 4$ and presented as mean \pm SD $(n=6)$ of two PCR analyses. Expression level in untreated rats (black) is arbitrary taken equal to $1 .{ }^{*} \mathrm{p} \leq 0.05$ vs control.

expression level (liver, placenta, fetal spleen and placenta) showed that $A B C D 2$ expression is very low (Fig. 5A). In whole brain and in substructures of central nervous system, expression level of $N R 1 H 3$ is relatively low and inversely correlates with the highest expression level of $A B C D 2$ (Fig. 5B). The whole results showing the compared expression level of $A B C D 2$ and $N R 1 H 3$ in tissues belonging to cardiovascular system, immune system, digestive system, fetal and other adult tissues show a quite equivalent inverse correlation with some exceptions for instance in heart and lymph nodes (Fig. S1).

\section{Discussion}

LXR activation has been shown to down-regulate the $A B C D 2$ expression in vitro [28]. The availability of GSK(17), a very efficient synthetic LXR antagonist [32], prompted us to study the effect of this molecule in different cell lines. Treatments with the antagonist 22S-HC and the endogenous agonist 22R-HC were carried out in parallel. Our results clearly show that treatment with $\mathrm{LXR} \alpha$ antagonists induces the expression of $A B C D 2$ in HepG2 hepatoma cells and X-ALD skin fibroblasts and confirm that 22R-HC treatment results in the opposite effect. However, in HepG2 cells, the observed variations remain quite low (1.5-2-fold increase) as compared with the levels of up-regulation measured after a treatment with thyroid hormone and thyromimetics [20]. Interestingly, both $A B C D 3$ and $C T N N B 1$ genes were found to be induced by LXR antagonists whereas expression of $A C O X 1$ remained unchanged whatever the treatment and the cell type. This latter result was unexpected since the well-characterized LXR synthetic ligand, T0901317, was demonstrated to induce a small increase of hepatic Acox1 expression in mice [38]. Ligand differences might explain this discrepancy and it is also possible that the concentrations used in our assays were not sufficient to observe any changes.

To see whether the use of LXR antagonists could improve the redox status and reduce the VLCFA accumulation, we treated X-ALD fibroblasts with the LXR antagonists GSK(17) and 22S-HC. Although VLCFA content was not significantly modified, MUFA (C20:1, C22:1 and $\mathrm{C} 24: 1$ ) as well as $\mathrm{C} 24: 6 \mathrm{n}-3$ levels appeared to be reduced by the treatments with LXR antagonists, mainly 22S-HC. In mirror, MUFA levels were found to be increased by the 22R-HC treatment. With the exception of saturated fatty acids, these observations, which have to be statistically consolidated, are in quite good agreement with the suspected role of $A B C D 2$ towards these fatty acids [13-15]. However, these results may not be strictly dependent on $A B C D 2$ expression since the level of $A B C D 2$ expression in human primary fibroblasts is very low [4] and that the induction level due to LXR antagonists is not elevated. Besides, the stearoyl-CoA desaturase-1 (SCD1) which converts C18:0 to C18:1 has been shown to be induced by LXR agonists [39]. It is therefore consistent to find an increase level of MUFA in 22R-HC treated cells and the opposite in cells treated with LXR antagonists. Concerning ROS production, a decrease was observed in X-ALD fibroblasts treated with the LXR antagonists while 22R-HC treatment resulted in increased ROS production. Oxidative stress changes may result from the moderated alterations observed in MUFA and be a consequence of ABCD2 induction or repression. However, it is also tempting to speculate that an effect of LXR antagonists on other targets mediated the ROS related effects. For instance, the Wnt/ $\beta$-catenin pathway should be explored in detail since an important role of $\beta$-catenin signaling for liver protection against oxidative stress has previously been demonstrated [40].

Reinvestigation of the samples collected from the study of the effect of 22S-HC in rats by Kase et al. [34], showed increased expression levels of $A b c d 2, A b c d 3$, and Ctnnb1 genes upon 22S-HC treatment. Further studies would be necessary to see whether the GSK(17) compound is also efficient in vivo and to see whether induction of the target genes can be found in other tissues related to X-ALD such as brain, spinal
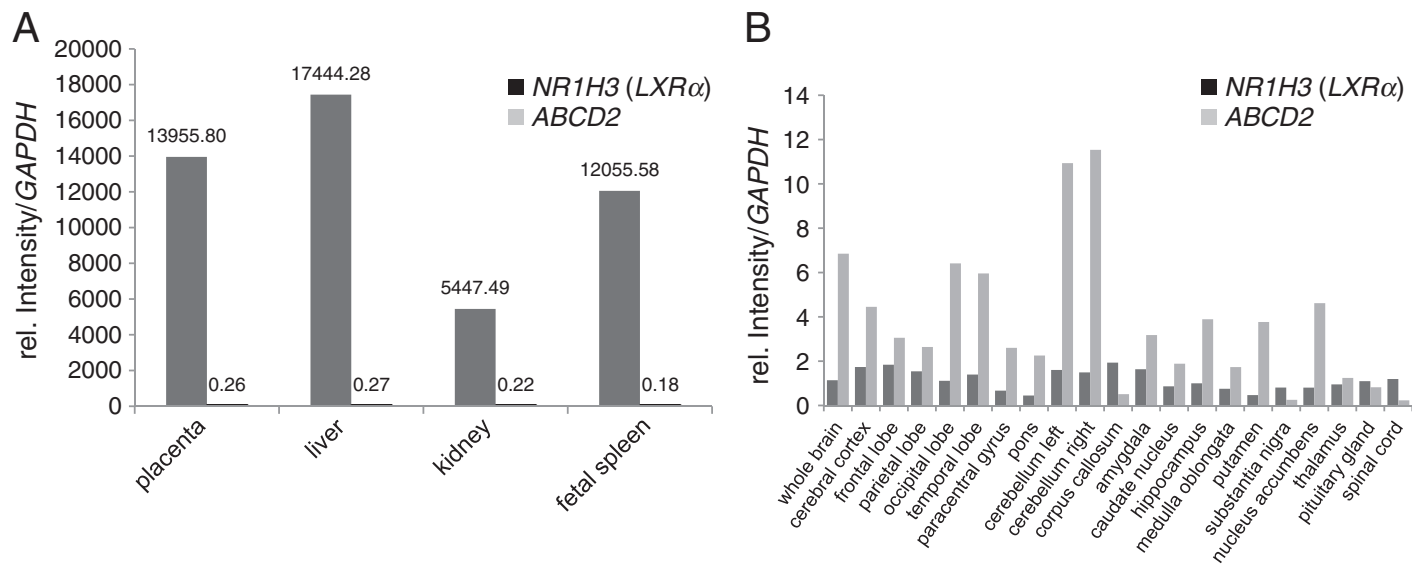

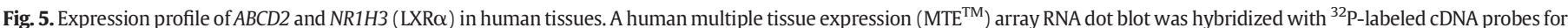

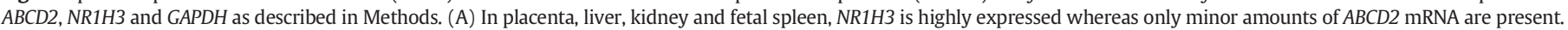
(B) In the central nervous system, $A B C D 2$ is relatively highly expressed and correlates with low expression of $N R 1 H 3$. 
cord, testis and adrenals. Meanwhile, these results together with the results obtained in vitro show for the first time that LXR antagonists can induce $A B C D 2$ and other genes of interest both in vitro and in vivo.

In order to gain additional knowledge on the expression level of $A B C D 2$ and NR1H3 (LXR $\alpha)$ genes in human tissues, we performed multiple tissue expression arrays. The general conclusion of this exploration underlines a possible inverse correlation between the expression level of these two genes since $A B C D 2$ appears very weakly expressed in the tissues containing the highest level of $N R 1 H 3$ and vice versa. Obviously, it is not a strict correlation and the expression level of $A B C D 2$ cannot be restricted to a simple and unique dependency to LXR $\alpha$. LXR $\beta$ is probably another actor involved in the regulation of $A B C D 2$ as well as many other nuclear receptors and transcription factors. Interestingly, $A B C D 2$ was recently demonstrated to be regulated by $\beta$-catenin [29] and we show in this study that CTNBB1 expression increases through LXR antagonist treatments. These results suggest the presence of a possible loop of amplification involving both the metabolic adaptation due to LXRs and oxysterol levels and the cell signaling pathways in relation with $\beta$ catenin. Besides, as discussed in the introduction, $A B C D 2$ is a target gene for various pathways in relation with LXR activation (PPAR $\alpha$, TR $\alpha / \beta$, SREBPs ...). Many cross-talks exist between these molecular pathways. For instance, deiodinase 2, which converts T4 to T3, is repressed by 22R-HC in HepG2 cells [41] and unliganded TR $\beta$ represses LXR $\alpha$ transactivation [42,43]. Indirect regulation of PPAR $\alpha$ ligands such as fibrates was supposed to involve LXR $\alpha$ [18]. The effects of PUFAs on $A B C D 2$ expression probably involve several mechanisms, one of them being possibly LXR antagonization [23]. The regulatory pathways and cross-talks targeting $A B C D 2$ promoter are summarized in Fig. 6 and confirm that $A B C D 2$ is a main target of several converging regulatory pathways in relation with each other. Such a complex regulation is likely to be linked to a crucial functional role of the $\mathrm{ABCD} 2$ protein into the peroxisomal membrane for the peroxisomal metabolism and important physiological functions that remains to be discovered. This is coherent with the role attributed to $A B C D 2$ in the fatty acid homeostasis [14]. In the context of X-ALD, the crosstalk between LXR $\alpha$ and the Wnt/3catenin pathway might be particularly interesting since positive consequences might be expected towards inflammation control [44] and myelination process $[31,45]$. The roles of LXR receptors (LXR $\alpha$ and LXRß) in lipid homeostasis [46], inflammation [47], and steroid synthesis [48] are very well documented in peripheral tissues. In the nervous system, both LXR isoforms are expressed and are thought to control cholesterol homeostasis [49]. The observed disturbances in LXR doubleknockout mice demonstrate the importance of LXR in brain [50]. LXR activation in brain is apparently associated with deleterious effects. The levels of hydroxycholesterol species (22R-HC, 24S-HC, and 25-HC which are ligands of both LXR isoforms) are usually altered in neurodegenerative diseases. 24S-HC, also known as cerebrosterol, seems to be a key element of inflammation and demyelination [51]. In neural cells, 24S-HC induces inflammatory genes such as cyclooxygenase-2 and phospholipase A2. It is therefore tempting to speculate that the use of LXR antagonists, if they can cross the blood-brain barrier and remain sufficiently bioavailable, may be interesting in the context of neurodegenerative diseases.

Altogether, this study confirms that agonists of LXR repress $A B C D 2$ expression and demonstrates for the first time that LXR antagonists induce $A B C D 2$ expression in vitro in X-ALD fibroblasts and HepG2 cells as well as in vivo in rat liver. It makes the proof of concept that synthetic LXR antagonists, which are in development to treat dyslipidemia

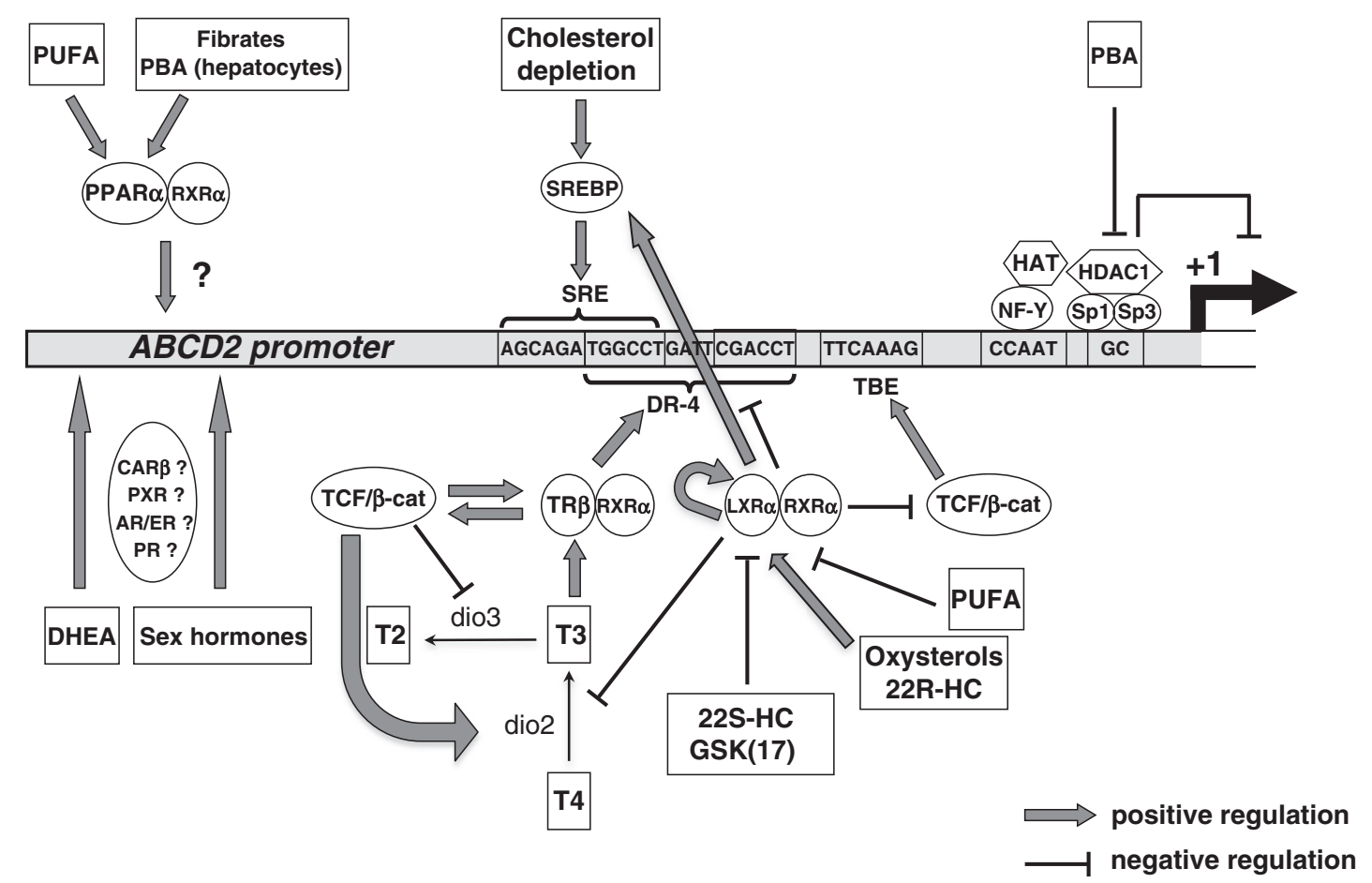

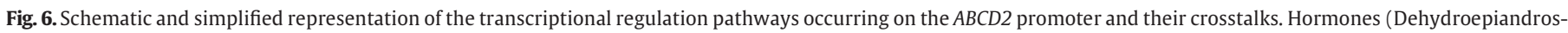

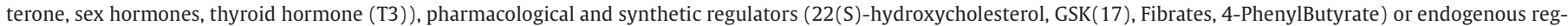

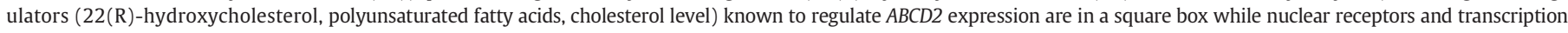

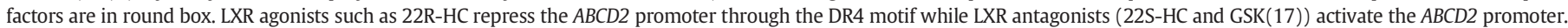

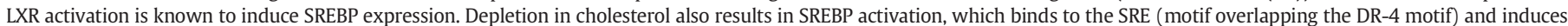

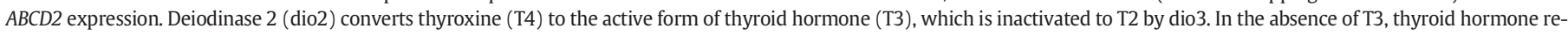

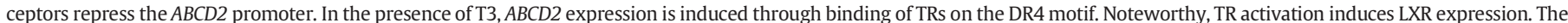

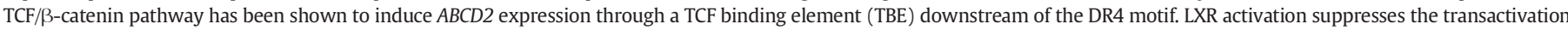

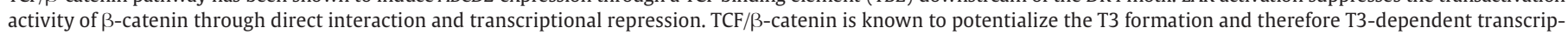
tion. $\beta$-catenin expression is induced by T3. Moreover, physical interactions between $\beta$-catenin and either TRs or LXRs have been also described improving their effects. 
[32,52-54] can be used as pharmacological inducers of $A B C D 2$. Further studies are needed to confirm whether such molecules, by their ability to induce $A B C D 2$ and to reduce oxidative stress, may have a therapeutic value in the context of X-ALD.

Supplementary data to this article can be found online at http://dx. doi.org/10.1016/j.bbalip.2013.11.003.

\section{Acknowledgements}

We are very grateful to William J Zuercher (GlaxoSmithKline, North Carolina) for providing us the synthetic LXR antagonist GSK(17). We also thank G. Bessede and J.-P. Pais de Barros (Plateforme de lipidomique, Dijon) for lipid analysis and A. Oblette for technical assistance. The study was supported by grants from the ELA foundation (ELA 2010-039IP1) and the Regional council of Burgundy.

\section{References}

[1] D. Trompier, S. Savary, X-linked Adrenoleukodystrophy, Morgan \& Claypool Life Sciences, 2013.

[2] L. Bezman, A.B. Moser, G.V. Raymond, P. Rinaldo, P.A. Watkins, K.D. Smith, N.E. Kass, H.W. Moser, Adrenoleukodystrophy: incidence, new mutation rate, and results of extended family screening, Ann. Neurol. 49 (2001) 512-517.

[3] J. Mosser, A.M. Douar, C.O. Sarde, P. Kioschis, R. Feil, H. Moser, A.M. Poustka, J.L. Mandel, P. Aubourg, Putative X-linked adrenoleukodystrophy gene shares unexpected homology with ABC transporters, Nature 361 (1993) 726-730.

[4] C. Wiesinger, M. Kunze, G. Regelsberger, S. Forss-Petter, J. Berger, Impaired very long-chain Acyl-CoA beta-oxidation in human X-linked adrenoleukodystrophy fibroblasts is a direct consequence of ABCD1 transporter dysfunction, J. Biol. Chem 288 (2013) 19269-19279.

[5] G. Lombard-Platet, S. Savary, C.O. Sarde, J.L. Mandel, G. Chimini, A close relative of the adrenoleukodystrophy (ALD) gene codes for a peroxisomal protein with a specific expression pattern, Proc. Natl. Acad. Sci. U. S. A. 93 (1996) 1265-1269.

[6] A. Holzinger, S. Kammerer, J. Berger, A.A. Roscher, cDNA cloning and mRNA expression of the human adrenoleukodystrophy related protein (ALDRP), a peroxisomal ABC transporter, Biochem. Biophys. Res. Commun. 239 (1997) 261-264.

[7] K. Kamijo, S. Taketani, S. Yokota, T. Osumi, T. Hashimoto, The 70-kDa peroxisomal membrane protein is a member of the Mdr (P-glycoprotein)-related ATP-binding protein superfamily, J. Biol. Chem. 265 (1990) 4534-4540.

[8] L.T. Braiterman, S. Zheng, P.A. Watkins, M.T. Geraghty, G. Johnson, M.C. McGuinness, A.B. Moser, K.D. Smith, Suppression of peroxisomal membrane protein defects by peroxisomal ATP binding cassette (ABC) proteins, Hum. Mol. Genet. 7 (1998) 239-247.

[9] E. Flavigny, A. Sanhaj, P. Aubourg, N. Cartier, Retroviral-mediated adrenoleukodystrophy-related gene transfer corrects very long chain fatty acid metabolism in adrenoleukodystrophy fibroblasts: implications for therapy, FEBS Lett. 448 (1999) 261-264.

[10] S. Kemp, H.M. Wei, J.F. Lu, L.T. Braiterman, M.C. McGuinness, A.B. Moser, P.A. Watkins, K.D. Smith, Gene redundancy and pharmacological gene therapy: implications for X-linked adrenoleukodystrophy, Nat. Med. 4 (1998) 1261-1268.

[11] A. Netik, S. Forss-Petter, A. Holzinger, B. Molzer, G. Unterrainer, J. Berger, Adrenoleukodystrophy-related protein can compensate functionally for adrenoleukodystrophy protein deficiency (X-ALD): implications for therapy, Hum. Mol Genet. 8 (1999) 907-913.

[12] A. Pujol, I. Ferrer, C. Camps, E. Metzger, C. Hindelang, N. Callizot, M. Ruiz, T. Pampols, M. Giros, J.L. Mandel, Functional overlap between ABCD1 (ALD) and ABCD2 (ALDR) transporters: a therapeutic target for X-adrenoleukodystrophy, Hum. Mol. Genet. 13 (2004) 2997-3006.

[13] C.W. van Roermund, W.F. Visser, L. Ijlst, H.R. Waterham, R.J. Wanders, Differential substrate specificities of human $A B C D 1$ and $A B C D 2$ in peroxisomal fatty acid beta-oxidation, Biochim. Biophys. Acta Mol. Cell Biol. Lipids 1811 (2010) 148-152.

[14] S. Fourcade, M. Ruiz, C. Camps, A. Schluter, S.M. Houten, P.A. Mooyer, T. Pampols, G. Dacremont, R.J. Wanders, M. Giros, A. Pujol, A key role for the peroxisomal ABCD2 transporter in fatty acid homeostasis, Am. J. Physiol. Endocrinol. Metab. 296 (2009) E211-E221.

[15] E.C. Genin, F. Geillon, C. Gondcaille, A. Athias, P. Gambert, D. Trompier, S. Savary, Substrate specificity overlap and interaction between adrenoleukodystrophy protein (ALDP/ABCD1) and adrenoleukodystrophy-related protein (ALDRP/ABCD2), J. Biol. Chem. 286 (2011) 8075-8085.

[16] J. Liu, N.S. Sabeva, S. Bhatnagar, X.A. Li, A. Pujol, G.A. Graf, ABCD2 is abundant in adipose tissue and opposes the accumulation of dietary erucic acid (C22:1) in fat, J. Lipid Res. 51 (2010) 162-168.

[17] I. Weinhofer, S. Forss-Petter, M. Zigman, J. Berger, Cholesterol regulates ABCD2 expression: implications for the therapy of X-linked adrenoleukodystrophy, Hum. Mol. Genet. 11 (2002) 2701-2708.

[18] S. Fourcade, S. Savary, S. Albet, D. Gauthe, C. Gondcaille, T. Pineau, J. Bellenger, M. Bentejac, A. Holzinger, J. Berger, M. Bugaut, Fibrate induction of the adrenoleukodystrophy-related gene (ABCD2): promoter analysis and role of the peroxisome proliferator-activated receptor PPARalpha, Eur. J. Biochem. 268 (2001) 3490-3500.
[19] S. Fourcade, S. Savary, C. Gondcaille, J. Berger, A. Netik, F. Cadepond, M. El Etr, B. Molzer, M. Bugaut, Thyroid hormone induction of the adrenoleukodystrophy-related gene (ABCD2), Mol. Pharmacol. 63 (2003) 1296-1303.

[20] E.C. Genin, C. Gondcaille, D. Trompier, S. Savary, Induction of the adrenoleukodystrophy-related gene (ABCD2) by thyromimetics, J. Steroid Biochem. Mol. Biol. 116 (2009) 37-43.

[21] I. Weinhofer, M. Kunze, H. Rampler, S. Forss-Petter, J. Samarut, M. Plateroti, J. Berger, Distinct modulatory roles for thyroid hormone receptors TRalpha and TRbeta in SREBP1-activated ABCD2 expression, Eur. J. Cell Biol. 87 (2008) 933-945.

[22] F. Gueugnon, C. Gondcaille, S. Leclercq, J. Bellenger, S. Bellenger, M. Narce, T. Pineau, F. Bonnetain, S. Savary, Dehydroepiandrosterone up-regulates the adrenoleukodystrophy-related gene (ABCD2) independently of PPARalpha in rodents, Biochimie 89 (2007) 1312-1321.

[23] S. Leclercq, J. Skrzypski, A. Courvoisier, C. Gondcaille, F. Bonnetain, A. Andre, J.M. Chardigny, S. Bellenger, J. Bellenger, M. Narce, S. Savary, Effect of dietary polyunsaturated fatty acids on the expression of peroxisomal ABC transporters, Biochimie 90 (2008) 1602-1607.

[24] C. Gondcaille, M. Depreter, S. Fourcade, M.R. Lecca, S. Leclercq, P.G. Martin, T. Pineau, F. Cadepond, M. Eletr, N. Bertrand, A. Beley, S. Duclos, D. De Craemer, F. Roels, S. Savary, M. Bugaut, Phenylbutyrate up-regulates the adrenoleukodystrophy-related gene as a nonclassical peroxisome proliferator, J. Cell Biol. 169 (2005) 93-104.

[25] M. Bugaut, S. Fourcade, C. Gondcaille, F. Gueugnon, M. Depreter, F. Roels, A. Netik, J. Berger, P. Martin, T. Pineau, F. Cadepond, M. El Etr, S. Savary, Pharmacological induction of redundant genes for a therapy of X-ALD: phenylbutyrate and other compounds, Adv. Exp. Med. Biol. 544 (2003) 281-291.

[26] S. Fourcade, M. Ruiz, C. Guilera, E. Hahnen, L. Brichta, A. Naudi, M. Portero-Otin, G. Dacremont, N. Cartier, R. Wanders, S. Kemp, J.L. Mandel, B. Wirth, R. Pamplona, P. Aubourg, A. Pujol, Valproic acid induces antioxidant effects in X-linked adrenoleukodystrophy, Hum. Mol. Genet. 19 (2010) 2005-2014.

[27] B.A. Janowski, P.J. Willy, T.R. Devi, J.R. Falck, D.J. Mangelsdorf, An oxysterol signalling pathway mediated by the nuclear receptor LXR alpha, Nature 383 (1996) 728-731.

[28] I. Weinhofer, M. Kunze, H. Rampler, A.L. Bookout, S. Forss-Petter, J. Berger, Liver X receptor alpha interferes with SREBP1c-mediated Abcd2 expression. Novel cross-talk in gene regulation, J. Biol. Chem. 280 (2005) 41243-41251.

[29] C.Y. Park, H.S. Kim, J. Jang, H. Lee, J.S. Lee, J.E. Yoo, D.R. Lee, D.W. Kim, ABCD2 is a direct target of beta-catenin and TCF-4: implications for X-linked adrenoleukodystrophy therapy, PLoS ONE 8 (2013) e56242.

[30] G. Shackleford, J. Makoukji, J. Grenier, P. Liere, D. Meffre, C. Massaad, Differential regulation of Wnt/beta-catenin signaling by Liver X receptors in Schwann cells and oligodendrocytes, Biochem. Pharmacol. 86 (2013) 106-114

[31] J. Makoukji, G. Shackleford, D. Meffre, J. Grenier, P. Liere, J.M. Lobaccaro, M. Schumacher, C. Massaad, Interplay between LXR and Wnt/beta-catenin signaling in the negative regulation of peripheral myelin genes by oxysterols, J. Neurosci. 31 (2011) 9620-9629.

[32] W.J. Zuercher, R.G. Buckholz, N. Campobasso, J.L. Collins, C.M. Galardi, R.T. Gampe, S.M. Hyatt, S.L. Merrihew, J.T. Moore, J.A. Oplinger, P.R. Reid, P.K. Spearing, T.B. Stanley, E.L. Stewart, T.M. Willson, Discovery of tertiary sulfonamides as potent Liver X receptor antagonists, J. Med. Chem. 53 (2010) 3412-3416.

[33] E.T. Kase, G.H. Thoresen, S. Westerlund, K. Hojlund, A.C. Rustan, M. Gaster, Liver X receptor antagonist reduces lipid formation and increases glucose metabolism in myotubes from lean, obese and type 2 diabetic individuals, Diabetologia 50 (2007) 2171-2180

[34] E.T. Kase, N. Nikolic, N. Pettersen Hessvik, A.K. Fjeldheim, J. Jensen, G.H. Thoresen, A.C. Rustan, Dietary supplementation with 22-S-hydroxycholesterol to rats reduces body weight gain and the accumulation of liver triacylglycerol, Lipids 47 (2012) 483-493.

[35] M. Baarine, P. Andreoletti, A. Athias, T. Nury, A. Zarrouk, K. Ragot, A. Vejux, J.M. Riedinger, Z. Kattan, G. Bessede, D. Trompier, S. Savary, M. Cherkaoui-Malki, G. Lizard, Evidence of oxidative stress in very long chain fatty acid - treated oligodendrocytes and potentialization of ROS production using RNA interference-directed knockdown of ABCD1 and ACOX1 peroxisomal proteins, Neuroscience 213 (2012) 1-18.

[36] C.R. Vargas, M. Wajner, L.R. Sirtori, L. Goulart, M. Chiochetta, D. Coelho, A. Latini, S. Llesuy, A. Bello Klein, R. Giugliani, M. Deon, C.F. Mello, Evidence that oxidative stress is increased in patients with X-linked adrenoleukodystrophy, Biochim. Biophys. Acta 1688 (2004) 26-32.

[37] S. Fourcade, J. Lopez-Erauskin, J. Galino, C. Duval, A. Naudi, M. Jove, S. Kemp, F. Villarroya, I. Ferrer, R. Pamplona, M. Portero-Otin, A. Pujol, Early oxidative damage underlying neurodegeneration in X-adrenoleukodystrophy, Hum. Mol. Genet. 17 (2008) 1762-1773.

[38] T. Hu, P. Foxworthy, A. Siesky, J.V. Ficorilli, H. Gao, S. Li, M. Christe, T. Ryan, G. Cao, P. Eacho, M.D. Michael, L.F. Michael, Hepatic peroxisomal fatty acid beta-oxidation is regulated by liver X receptor alpha, Endocrinology 146 (2005) 5380-5387.

[39] X. Zhang, J. Liu, W. Su, J. Wu, C. Wang, X. Kong, J.A. Gustafsson, J. Ding, X. Ma, Y. Guan, Liver X receptor activation increases hepatic fatty acid desaturation by the induction of SCD1 expression through an LXRalpha-SREBP1c-dependent mechanism, J. Diabetes (2013), http://dx.doi.org/10.1111/1753-0407.12081.

[40] G.Z. Tao, N. Lehwald, K.Y. Jang, J. Baek, B. Xu, M.B. Omary, K.G. Sylvester, Wnt/beta-catenin signaling protects mouse liver against oxidative stress-induced apoptosis through the inhibition of forkhead transcription factor FoxO3, J. Biol. Chem. 288 (2013) 17214-17224.

[41] M.A. Christoffolete, M. Doleschall, P. Egri, Z. Liposits, A.M. Zavacki, A.C. Bianco, B. Gereben, Regulation of thyroid hormone activation via the liver X-receptor/retinoid X-receptor pathway, J. Endocrinol. 205 (2010) 179-186.

[42] K. Kawai, S. Sasaki, H. Morita, T. Ito, S. Suzuki, H. Misawa, H. Nakamura, Unliganded thyroid hormone receptor-beta1 represses liver $\mathrm{X}$ receptor alpha/oxysterol-dependent transactivation, Endocrinology 145 (2004) 5515-5524. 
[43] K. Hashimoto, R.N. Cohen, M. Yamada, K.R. Markan, T. Monden, T. Satoh, M. Mori, F.E. Wondisford, Cross-talk between thyroid hormone receptor and liver X receptor regulatory pathways is revealed in a thyroid hormone resistance mouse model, J. Biol. Chem. 281 (2006) 295-302.

[44] C. Halleskog, J. Mulder, J. Dahlstrom, K. Mackie, T. Hortobagyi, H. Tanila, L. Kumar Puli, K. Farber, T. Harkany, G. Schulte, WNT signaling in activated microglia is proinflammatory, Glia 59 (2011) 119-131.

[45] K. Nelissen, M. Mulder, I. Smets, S. Timmermans, K. Smeets, M. Ameloot, J.J Hendriks, Liver X receptors regulate cholesterol homeostasis in oligodendrocytes, J. Neurosci. Res. 90 (2012) 60-71.

[46] S.M. Ulven, K.T. Dalen, J.A. Gustafsson, H.I. Nebb, LXR is crucial in lipid metabolism, Prostaglandins Leukot. Essent. Fat. Acids 73 (2005) 59-63.

[47] N. Zelcer, P. Tontonoz, Liver X receptors as integrators of metabolic and inflammatory signaling, J. Clin. Invest. 116 (2006) 607-614.

[48] C.L. Cummins, D.H. Volle, Y. Zhang, J.G. McDonald, B. Sion, A.M. Lefrancois-Martinez, F. Caira, G. Veyssiere, D.J. Mangelsdorf, J.M. Lobaccaro, Liver X receptors regulate adrenal cholesterol balance, J. Clin. Invest. 116 (2006) 1902-1912.

[49] K.D. Whitney, M.A. Watson, J.L. Collins, W.G. Benson, T.M. Stone, M.J. Numerick, T.K. Tippin, J.G. Wilson, D.A. Winegar, S.A. Kliewer, Regulation of cholesterol homeostasis by the liver X receptors in the central nervous system, Mol. Endocrinol. 16 (2002) 1378-1385.

[50] L. Wang, G.U. Schuster, K. Hultenby, Q. Zhang, S. Andersson, J.A. Gustafsson, Liver X receptors in the central nervous system: from lipid homeostasis to neuronal degeneration, Proc. Natl. Acad. Sci. U. S. A. 99 (2002) 13878-13883.

[51] I. Bjorkhem, S. Meaney, Brain cholesterol: long secret life behind a barrier, Arterioscler. Thromb. Vasc. Biol. 24 (2004) 806-815.

[52] A. Aoyama, K. Endo-Umeda, K. Kishida, K. Ohgane, T. Noguchi-Yachide, H. Aoyama, M. Ishikawa, H. Miyachi, M. Makishima, Y. Hashimoto, Design, synthesis, and biological evaluation of novel transrepression-selective liver X receptor (LXR) ligands with 5,11-dihydro-5-methyl-11-methylene-6H-dibenz[b, e]azepin-6-one skeleton, J. Med. Chem. 55 (2012) 7360-7377.

[53] T. Noguchi-Yachide, A. Aoyama, M. Makishima, H. Miyachi, Y. Hashimoto, Liver X receptor antagonists with a phthalimide skeleton derived from thalidomide-related glucosidase inhibitors, Bioorg. Med. Chem. Lett. 17 (2007) 3957-3961.

[54] X. Jiao, D.J. Kopecky, B. Fisher, D.E. Piper, M. Labelle, S. McKendry, M. Harrison, S. Jones, J. Jaen, A.K. Shiau, P. Escaron, J. Danao, A. Chai, P. Coward, F. Kayser, Discovery and optimization of a series of liver X receptor antagonists, Bioorg. Med. Chem. Lett. 22 (2012) 5966-5970. 